\title{
The Test Method of Smart Substation Configuration Description File Based on Business Rules
}

\author{
Yanjun $\mathrm{Li}^{1}$, Xiliang Ding ${ }^{2,}$, Rongrong Zhan ${ }^{1}$ and Xiurong Gao ${ }^{2}$ \\ ${ }^{1}$ The State Key Laboratory for security and energy saving, China Electric Power Research Institute \\ Haidian District, Beijing 100192, China \\ 2 Shandong Roof innovation technology Co.Ltd, Jinan 250101, Shandong, China \\ *email: dingxiliang@tech-roof.com
}

Keywords: Substation configuration description; smart substation; configuration description.

Abstract: Smart substation is an intelligent substation which adopts advanced, reliable and ecofriendly techniques. It can finish the basic functions of collection, measure, protection and test automatically, meanwhile, advanced capabilities like automatic control, intelligent adjustment and online decision analysis can be realized, either. As one of the core platforms in strong smart grid, smart substation has not long but the rapid development and broad prospects. At present, the standardized design specification applicable to the relay protection and assist device of smart substation has been released in succession. However, the plant parameters of smart substation, for example, function configuration, are described by each manufacturer separately, and it is not enough to form a complete second allocation standard model. This paper provides a technical proposal which test Substation Configuration Description (SCD) file of smart substation based on business rules, and it can be roughly divided into 3 steps: the definition of basic model, the definition of project template and SCD file test. The classification of templates applied in the definition is listed under relevant steps. What's more, detailed steps are demonstrated and explained under every key step. And an example of standardized smart device template is given at the end of this paper.

\section{Introduction}

As the smart substation is energetically promoted, the standardized design specification applicable to the relay protection and assist device of smart substation has been proposed in succession. Although information like the functional configuration of relay protection under different voltage level and primary connection mode is set, it has been described in ICD, while the description is made on the basis of SCL model of each manufacturer. Although certain relevance can be guaranteed according to some standardized practice in relative standard, the complete second allocation standard model cannot be formed. So establishing a standardized model which can be used in detection is a technical difficulty.

Recent communication technology and information processing technology are applied in smart substation, compared with conventional substation; the structure and pattern are revolutionized. In conventional substation, the message communication among devices is realized by using cables and the circuit information among terminals is described by design layout, while in the smart substation, the information communication which fits IEC61850 is realized from network signals and the circuit information among terminals is described by the Substation Configuration Description (SCD) files, which fit SCL semantics. The concept of virtual terminal is promoted corresponding to actual terminal to make it more understandable for professional [1][2].

Domestic SCD documents are basically designed by the project planners or adjustors who make one-to-one association between input virtual terminal and output virtual terminal, also the virtual secondary circuit is formed and written into SCD documents, since each substation project should be done again, which leads the circuit allocation workload of each substation is heavy and the reusability is poor. What's more, the amount of virtual circuits in each smart substation is relatively huge, and the exam and verification of these circuits are conducted by field commissioning test, while the circuit 
errors in SCD document may lead to the heavy workload of repeat commission in project commissioning field. If the allocation plan of smart device in SCD, device virtual terminal, virtual secondary circuit can be examined and verified on the basis of operation before project field commissioning, the commissioning efficiency at project site can be increased [3].

As the construction of smart substation is promoted, the device standardization level is greatly improved. Relevant technical specification and standard have been released which offer possibility to the test of smart substation allocation files based on operating rules.

\section{Technical proposal}

Compared with conventional substation, the structure and pattern of smart substation revolutionized. In conventional substation, signal transmission is realized by the connection of cables, and there are one-to-one correspond between signal and cable; while in smart substation, signals are transferred through the net in smart devices, and the cables can reflect the combination relation in communication at most, and it cannot describe the real functional interoperability and interworking. At present, the design of smart substation should focus on the design of the virtual terminal and circuit instead of secondary circuit design, and the communication pipes should be designed. The representation method of correspondence between virtual circuit signal and communication cable is involved. In most of designing institute, the virtual terminal and circuit are designed separately, and the physical connection graph is expressed separately, which leads to the disconnection between physical pipe and logical virtual circuit. The method in this paper aims to solve the problems above[4][5].

To realize the target, the technical plan is applied in this paper.

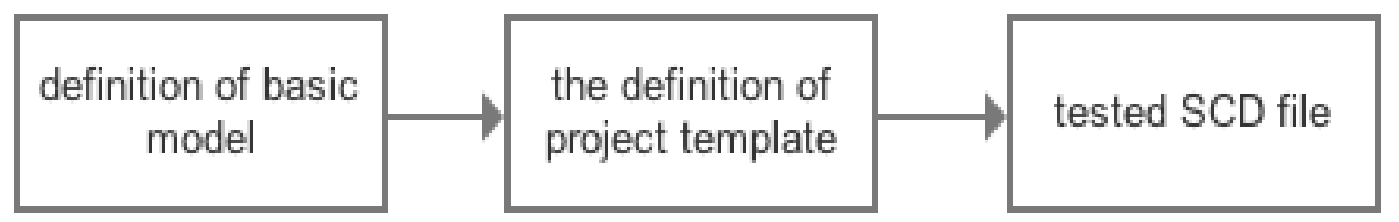

Fig.1 Total procedure of the test method

Step 1: definition of basic model, define the model class applied in the definition of project template

1. The model class applied in the definition of project template is demonstrated below:

a) Smart devices: template name, substation voltage level, primary connection mode, bay type, device function type, protection type, protection based type code; protection function code

b) Input virtual terminals: virtual terminal code, virtual terminal name, output virtual terminal

c) Output virtual terminals; virtual terminal code, virtual terminal name, output virtual terminal

d) Input virtual terminal subset: every smart device just have one virtual input terminal subset

e) Output virtual terminal subset: every smart device just have one virtual output terminal subset

f) Virtual secondary circuit, every secondary circuit includes input and output virtual terminal

g) Virtual secondary circuit group, the virtual secondary circuit means the set of secondary circuit between two smart devices which need communication

h) Bay: bay name, bay type

i) Design proposal rule: rule name, substation voltage level, and primary connection mode

step 2: use schema designed by basic model, combine with the relative standard specification in power industry, which includes standard smart device template, bay type template, substation design plan rule template; 


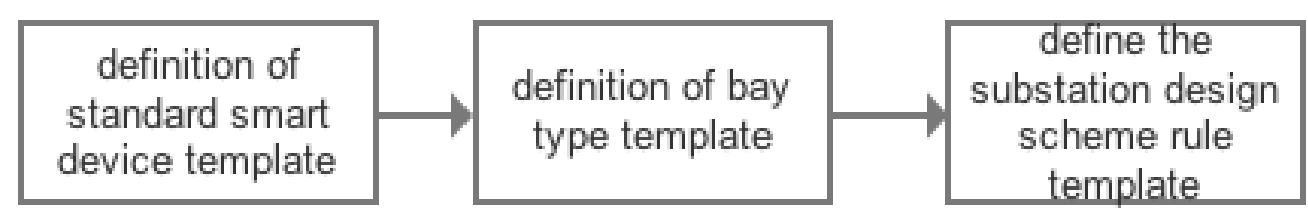

Fig.2 Engineering templates definition

1. Definition of standard smart device template

Combined with the general equipment specification, define the smart device template in step 1,

a) Define smart device templates with various primary connection modes, bay types and different substations with different voltage levels.

b) Input virtual terminal subset is well-defined in every smart device template.

c) Output virtual terminal subset is well-defined in every smart device template.

2. Definition of bay type template

a) Aiming at the function requirements of primary equipment bay to smart device, define general bay type template

b) The smart device and its type are well-defined in the bay of every template

c) The type of smart device must be the same as the one of standardized smart device template.

d) The virtual secondary circuit subset between every smart device and other smart device in bay type template should be well-defined.

3. Define the substation design scheme rule template

a) Define the substation design scheme rule templates on the basis of the voltage level and primary connection mode one by one

b) All the bay type involved in design scheme rule template are well-defined

c) There is a one-to-one match between every bay and bay type, which means the virtual secondary circuit subset between smart devices, is the same with the definition of bay type template.

d) The virtual secondary circuit subset between the smart device in every bay and other bay should be well-defined.

Step 3: SCD file test

The test of smart device allocation scheme

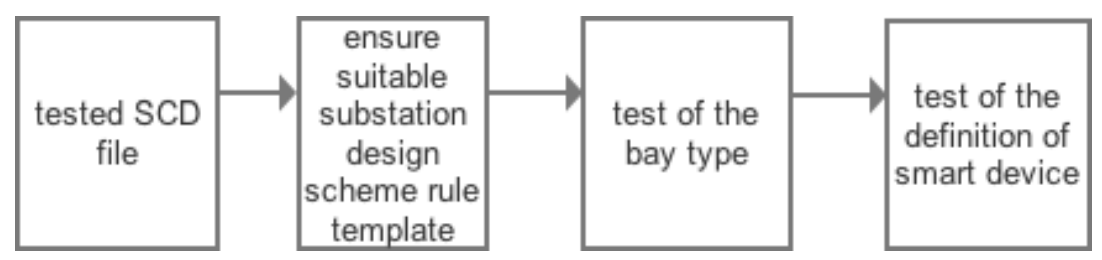

Fig.3 Program test process

1) On the basis of IEC61850 and the grammar definition of SCD file in Q/GDW1396-2012 IEC61850 Engineering relay protection application model, analyze the tested SCD, so the substation voltage level, primary connection mode, bay type and smart device which are defined in SCD file are obtained

2) According to the substation voltage level and primary connection mode, ensure suitable substation design scheme rule template during test.

3) Test of the bay type defined in substation design scheme rule template is the same as the one in SCD file or not, the judgment method is that every type of bay defined in substation design scheme rule template should have one living example

4) Test of the definition of smart device in every bay type defined in substation design scheme rule template is similar to the description in SCD file or not, the judgment method is that the type and quantity of smart device defined in substation design scheme rule template are similar to the description in SCD file. 
The test of virtual input and output terminal in smart device

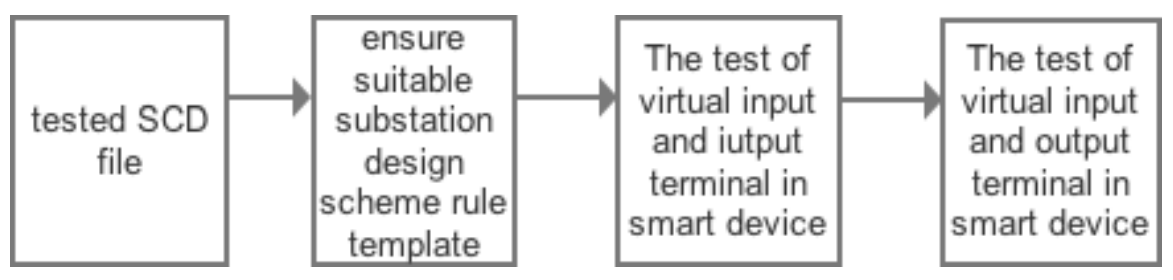

Fig.4 Terminal test process

1) On the basis of IEC61850 and the grammar definition of SCD file in Q/GDW1396-2012 << IEC61850 Engineering relay protection application model $>$, analyze the tested SCD, so the substation voltage level, primary connection mode, bay type, smart devices in bays, the input and output virtual terminals of smart devices which are defined in SCD file are obtained.

2) Ensure the standardized smart device template applied in test according to the substation voltage level, primary connection type, bay type, equipment function type, protection type and protection basic model number code.

3) Aiming at the similarity between the description of smart device in SCD file and standardized smart equipment, the judgement standards are:

a) The name and quantity of input virtual terminal of smart device in SCD file are similar to those in standardized smart device template.

b) The name and quantity of output virtual terminal of smart device in SCD file are similar to those in standardized smart device template.

4) Test all the smart devices in SCD file circularly

3. The test of virtual secondary circuit between smart devices

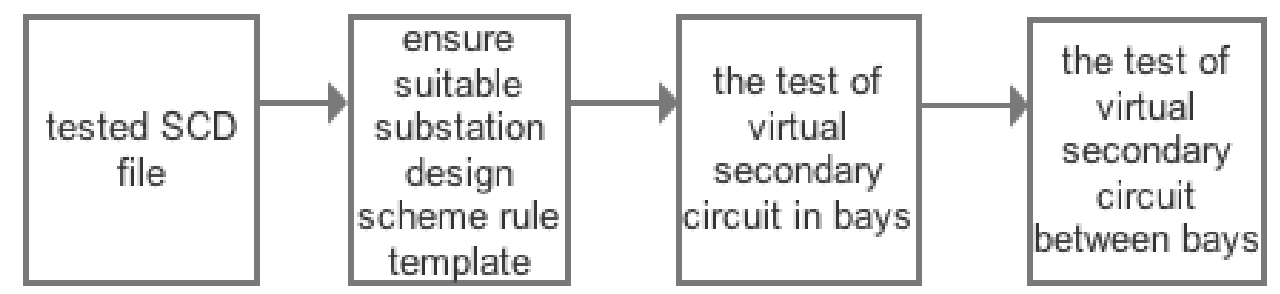

Fig.5 Test process of virtual secondary circuit

1) On the basis of IEC61850 and the grammar definition of SCD file in Q/GDW1396-2012 《IEC61850 Engineering relay protection application model》, analyze the tested SCD, so the substation voltage level, primary connection mode, bay type, smart device and virtual secondary circuit subset between smart devices which are defined in SCD file are obtained

2) On the basis of substation voltage level, primary main connection mode, ensure the substation design scheme rule template during test.

3) Test the virtual secondary circuit subset between one smart device and another one by one, and the test items are as follows:

a) The test of virtual secondary circuit in bays

Ensure the bay type template according to the bay of smart device, check the similarity between the smart device and the others in the bay, and the judgement method is that the circuit quantities in virtual signal circuit subset are the same, and the names of input and output virtual terminal are the same in every circuit

b) The test of virtual secondary circuit between bays

According to the selected substation design scheme rule template, check the similarity between the smart device and the others in the bay, and the judgement method is that the circuit quantities in 
virtual signal circuit subset are the same, and the names of input and output virtual terminal are the same in every circuit.

The example of standardized smart device template

\section{Template Property}

Tab.1 Template attributes

\begin{tabular}{|l|l|l|l|l|}
\hline \multicolumn{1}{|c|}{ Template } & 2-LP-DIF-20 & N-MU-20-L & N-BP-20 & N-BP-21 \\
\hline property & 220 & 220 & 220 & 220 \\
\hline Primstation voltage level & $\begin{array}{l}\text { Bus-doubled } \\
\text { circuit }\end{array}$ & $\begin{array}{l}\text { Bus-doubled } \\
\text { circuit }\end{array}$ & $\begin{array}{l}\text { Bus-doubled } \\
\text { circuit }\end{array}$ & $\begin{array}{l}\text { Bus-doubled } \\
\text { single segment } \\
\text { circuit }\end{array}$ \\
\hline Bay type & Circuit bay & Circuit bay & Bus bay & Bus bay \\
\hline Device function type & Relay protection & Merge cells & $\begin{array}{l}\text { Relay } \\
\text { protection }\end{array}$ & $\begin{array}{l}\text { Relay } \\
\text { protection }\end{array}$ \\
\hline Protection type & Circuit protection & NULL & $\begin{array}{l}\text { Bus } \\
\text { protection }\end{array}$ & Bus protection \\
\hline Protection basic model number code & A & NULL & A & A \\
\hline Protection code & PX & NULL & MPX & PX \\
\hline
\end{tabular}

P.S. When the device function code is not the same with relay protection, protection type, protection basic number code protection code are "NULL".

\section{The Example of terminal type template}

\section{Terminal Type Property}

Terminal type example 1

Tab.2 Terminal type example 1

\begin{tabular}{|c|c|}
\hline Terminal & 220-L \\
\hline Terminal type & Circuit terminal \\
\hline
\end{tabular}

The devices in terminal are listed as follow:

Tab.3 The devices in terminal

\begin{tabular}{|c|c|}
\hline Device & $\begin{array}{c}\text { Appropriate standardized smart device } \\
\text { template }\end{array}$ \\
\hline Circuit protection device & 2-LP-DIF-20 \\
\hline Circuit emerged unit & N-MU-20-L \\
\hline Circuit smart terminal & N-IT-CB-3P \\
\hline
\end{tabular}


Terminal type example 2

Tab.4 Terminal type example 2

\begin{tabular}{|l|l|}
\hline Terminal & $\mathbf{2 2 0 - B}$ \\
\hline Terminal type & Bus terminal \\
\hline
\end{tabular}

The devices in terminal are listed as follow:

Tab.5 The devices in terminal

\begin{tabular}{|l|l|}
\hline Device & $\begin{array}{l}\text { Appropriate standardized smart device } \\
\text { template }\end{array}$ \\
\hline Bus protection device & N-BP-20 \\
\hline Bus emerged unit & N-MU-20-B \\
\hline
\end{tabular}

\section{The Example of Virtual Secondary Circuit In Circuit terminal}

Tab.6 The Example of Virtual Secondary Circuit In Circuit terminal

\begin{tabular}{|l|l|l|l|}
\hline \multicolumn{2}{|l|}{ Circuit protection device } & Emerged unit \\
\hline Number & Input virtual terminal & Number & Output virtual terminal \\
\hline IN22 & $\begin{array}{l}\text { Rated delay time of } \\
\text { emerged unit 1 }\end{array}$ & OUT33 & $\begin{array}{l}\text { Rated time delay of } \\
\text { emerged unit }\end{array}$ \\
\hline IN24 & Protection of Ia1 & OUT34 & Protection of Ia1 \\
\hline IN25 & Protection of Ia2 & OUT35 & Protection of Ia2 \\
\hline IN26 & Protection of Ib1 & OUT36 & Protection of Ib1 \\
\hline IN27 & Protection of Ib2 & OUT37 & Protection of Ib2 \\
\hline IN28 & Protection of Ic1 & OUT38 & Protection of Ic1 \\
\hline IN29 & Protection of Ic2 & OUT39 & Protection of Ic2 \\
\hline IN30 & Protection of Ua1 & OUT57 & Circuit voltage UXa1 \\
\hline IN31 & Protection of Ua2 & OUT58 & Circuit voltage UXa2 \\
\hline
\end{tabular}

\section{Example of Substation Design Scheme Rule Template}

Tab.7 Design Scheme Rule Template

\begin{tabular}{|l|l|l|}
\hline Rule name & Property & Value \\
\hline \multirow{4}{*}{$20-11$} & Voltage level & 220 \\
\cline { 2 - 3 } & Primary main connection mode(220) & $\begin{array}{l}\text { Bus-doubled } \\
\text { connection }\end{array}$ \\
\cline { 2 - 3 } & Primary main connection mode(110) & $\begin{array}{l}\text { Single bus } \\
\text { segment }\end{array}$ \\
\hline
\end{tabular}

The terminals involved in substation design scheme template are demonstrated follow:

Tab.8 The terminals involved in design scheme

\begin{tabular}{|l|l|}
\hline Terminal type template & Terminal type \\
\hline $220-\mathrm{L}$ & Circuit terminal \\
\hline $110-\mathrm{L}$ & Circuit terminal \\
\hline $220-\mathrm{B}$ & Bus terminal \\
\hline $110-\mathrm{B}$ & Bus terminal \\
\hline
\end{tabular}


The example of circuit between terminals:

Tab.9 The example of circuit between terminals

\begin{tabular}{|l|l|l|l|}
\hline \multicolumn{2}{|l|}{ Circuit protection device } & \multicolumn{2}{l|}{ Bus protection } \\
\hline Code & Output virtual terminal & Code & Input virtual terminal \\
\hline OUT4 & $\begin{array}{l}\text { Phase A failure after } \\
\text { starting circuit breaker }\end{array}$ & IN22 & Phase A failure in circuit 1(branch 4) \\
\hline OUT5 & $\begin{array}{l}\text { Phase B failure after } \\
\text { starting circuit breaker }\end{array}$ & IN23 & Phase B failure in circuit 1(branch 4) \\
\hline OUT6 & $\begin{array}{l}\text { Phase C failure after } \\
\text { starting circuit breaker }\end{array}$ & IN24 & Phase C failure in circuit 1(branch 4) \\
\hline
\end{tabular}

\section{Conclusion}

This paper provides a test method of SCD file on the basis of a business rule, which is based on the great improvement of industrious device standardization level. It defines the model of business rule, standard smart device model, new terminal model and other project model. What's more, it automatically test the configuration plan of smart device in SCD file, input and output virtual terminal of smart device and virtual secondary circuit of smart device, so the file error can be detected after the design of substation project, which ensured the efficiency of design and test, and shortened the design cycle and test cycle.

\section{References}

[1]Y. Yang; L. Gao. Comparison method for differentiation of IEC 61850 based substation configuration files[C]. 2014 International Conference on Power System Technology; 2014:1796-1801

[2] Yongkang Zheng; Jiran Cai; Zhenyu Zhou; Research review and application prospect of secondary equipment condition monitoring[C]. 2016 International Conference on Smart Grid and Clean Energy Technologies (ICSGCE). 2016:290-295

[3] Qipeng Song; Wanxing Sheng; Lingfeng Kou; Smart substation integration technology and its application in distribution power grid[J]. CSEE Journal of Power and Energy Systems.2016:31-36

[4]R.Cosse; J.E.Bowen; H.T.Combs;Smart industrial substations[J]. IEEE Industry Applications Magazine.2005:12-20

[5] F. S. Al-Qahtani; S. A. Zummo; Spectral efficiency evaluation for selection combining diversity (SCD) scheme over slow fading[J]. IET Communications.2009:1443-1451

[6] Y. Yang; L. L. Song; Smart substation secondary system visualization and intelligent diagnosis based on improved SCD model[C]. International Conference on Renewable Power Generation (RPG 2015);2015:1-5 